\title{
A micro-analysis of Irish firm deaths during the financial crisis (2006-2010)
}

Research Article

\author{
Bernadette Power, Geraldine Ryan* and Justin Doran \\ University College Cork, Ireland
}

\begin{abstract}
This paper examines differences in the hazard rates of young, established and mature firms during the financial crisis, using microdata from more than 300,000 Irish firms. The findings confirm that firm size at the time of the crisis had the largest impact on the probability of exit. The liability of smallness was pronounced in mature cohorts. Industry conditions had a considerable effect on the hazard rate of young cohorts, as opposed to mature counterparts. Interestingly, agglomeration raised the hazard rates of younger cohorts only. By contrast, attributes of the labour force of the region largely influenced the hazard rates of more established firms. Firms founded before the crisis were significantly less likely to exit in the aftermath of the crisis, in comparison with firms founded just before or during the crisis, whereas more mature firms seem to be more sensitive to the economic cycle.
\end{abstract}

Keywords: firm deaths; firm exit; environmental conditions; financial crisis

(c) Sciendo

\section{INTRODUCTION}

For policymakers to fully comprehend the influence of enterprise deaths on innovation and economic development, in response to a macroeconomic shock, greater understanding of the determinants of enterprise deaths is required. For example, are new small firms more likely to fail than established or mature small firms? Are new large firms more likely to fail than mature large firms? Does industrial sector play a role in firm failure? Are new small firms in cities more likely to fail than new small firms in rural locations? Does it matter when the firm was established? During normal market conditions, small firms, young firms, firms that fail to innovative, modernise and remain competitive, and lifestyle firms with ageing owner-managers are more likely to die (Cefis and Marsili, 2005). While these determinants remain important during crisis periods, other factors, such as restricted access to finance, higher borrowing costs, and increased market risk can result in the death of otherwise healthy firms. While there are a lot of studies of new firm formation, growth and survival, little is known about the determinants of firm deaths and how these respond to changes in the business cycle (Ejermo and Xiao, 2014). In this paper, we examine the exit behaviour of more than 300,000 Irish firms of varying sizes and ages between 2006 and 2010.

A number of studies suggest that, since new, established and mature ${ }^{1}$ firms interact differently with the environment, different determinants influence their exit (Carreira and Teixeira, 2011b, Fackler et al., 2013, Bellone et al., 2008). Authors such as Audretsch and Mahmood (1995), Fotopoulos and Louri (2000), and Zarutskie and Yang (2016) argue that new firms are more likely to suffer in recessions, as their high dependence on bank funding restricts their access to credit (Carbo-Valverde et al., 2016). Established firms, on the other hand, are more likely to shrink than to close (Fort et al., 2013), as they are less likely to be credit rationed and reduced new firm entry rates during these crisis periods decreases pressure on them to compete (Carreira and Teixeira, 2011a). In comparison, mature firms threatened by creative destruction and inertia are more likely to fail, unless they quickly adapt to environmental changes and keep pace with innovation.

This paper examines the influence of determinants on the hazard rates of five cohorts of Irish firms, following the major environmental shock posed by the 2007 financial crisis. This shock had a significant effect on all aspects of

1 Typically, new firms are less than 2 years old, established firms are between 2 and 10 years old and mature firms are more than 10 years old. 
the economy, with the Irish Government issuing a broad state guarantee of Irish domestic banks in September 2008, followed by the recapitalisation of its two largest banks in February 2009, and an agreement with the International Monetary Fund, the European Central Bank, and the European Commission, for a three-year, $€ 67.5$ billion bailout in December 2010 (Bergin et al., 2011). Irish gross domestic product fell from $€ 48.95$ billion pre-crisis (2007) to a low of $€ 44.8$ billion during the crisis (2010). Throughout this time, unemployment rose from $5 \%$ in 2007 to $15.6 \%$ in 2010 , while enterprise death rates rose from $8 \%$ in 2006 to a peak of $13.5 \%$ at the height of the crisis in 2009 , thus making Ireland an interesting case to examine.

The paper makes two important contributions to the literature on firm deaths. First, by using a very broad representative sample of more than $80 \%$ of all enterprises in Ireland (NACE 4-digit Codes A-U between 2006 and 2010), we accurately characterise enterprise deaths over the financial crisis period, using an array of firm, industry, economic and regional determinants. Few empirical studies that focus on firm deaths include a broad-based sectoral analysis, except for Germany (Fackler et al., 2013, Fackler et al., 2014), and, to a certain extent, Sweden (Box, 2008). Most of the empirical studies focus on manufacturing firms, such as Carreira and Teixeira (2011b) for Portugal, Esteve-Pérez and Mañez-Castillejo (2008) for Spain, Bellone et al. (2008) for France, and Bernard and Jensen (2007) for the United States (US). Most of these studies emphasise that mature firms and new firms do not interact with the environment in the same way (Carreira and Teixeira, 2011b, Bellone et al., 2008). Second, with information on the year in which the firm was founded, we characterise enterprise deaths at different points in their lifecycle. The hazard rates of firms are examined for (1) the full sample; (2) firms founded prior to the crisis (broken into those founded prior to 1980, 1980-1989, 1990-1999, 2000-2005); and (3) firms founded during the crisis (20062010). We estimate the influence of firm, industry, economic and regional factors on the hazard rates of firms across these cohorts, using Cox proportional hazard $(\mathrm{CPH})$ models with an Efron correction for ties.

Briefly, this paper is structured as follows: we begin by locating our hypotheses in the extant literature. Next, we introduce our data and key variables, before reporting the results of the $\mathrm{CPH}$ models. Finally, we present our conclusions.

\section{THEORETICAL PERSPECTIVES AND MAIN HYPOTHESES}

Theoretical approaches taken in studies of firm deaths have generally, but not exclusively, adopted an organisational ecology (Geroski et al., 2010), an industrial economics (Carreira and Teixeira, 2011b) and/or resource based view perspective (Zúñiga-Vicente and Vicente-Lorente, 2006, Esteve-Pérez and Mañez-Castillejo, 2008). The ecological approach argues that firms are largely inert in the face of environmental change and thus face an increased risk of death (Zúñiga-Vicente and Vicente-Lorente, 2006), whereas the key tenet of the industrial economics approach is that the firm is powerless, unless it accumulates resources to overcome entry barriers and/or is selected by the market (Jovanovic, 1982). Within the resource-based view, the market selects firms with inimitable and nontradable resources that match the demand of the environment which it serves to survive (Esteve-Pérez and MañezCastillejo, 2008). The approach taken in this paper relies more on the industrial economics and organisational ecology approach than the resource-based view of the firm.

The competing theoretical explanations focus largely on the struggle of new firms to survive post-entry, given their 'newness'. This is referred to as the 'liability of newness' (Stinchcombe, 1965). This struggle to acquire resources is likely to be more severe during an economic shock. In addition, according to Barron et al. (1994), ageing itself brings two liabilities, which increase the risk of firm death: (1) the 'liability of obsolescence', where the structural inertia in the face of environmental change limits the firm's ability to make the necessary adjustments to survive; and (2) the 'liability of senescence', where increasing bureaucracy reduces the firm's efficiency, thus threatening its ability to survive. Mature firms face both these liabilities in a period of economic distress.

There is some evidence in support of the liability of ageing. Fackler et al. (2013) find that exit rates decline with age, supporting the industrial economics perspective - reaching a minimum at ages 15-18 and only then to rise again. In contrast, Esteve-Pérez and Mañez-Castillejo (2008) find that the hazard rate increases up to 20 years and then declines until the firm reaches the age of 35 , supporting the liability of adolescence. The liability of adolescence argues that firms can survive for a while with their initial stock of resources, but that failure rates reach a peak when these endowments are exhausted. Esteve-Pérez and Mañez-Castillejo (2008) find that the likelihood of exit rises considerably again for firms aged 75 and above, also supporting the liability of ageing. Mueller and Stegmaier (2015), in examining bankruptcy risks as opposed to firm exits in Germany, found evidence of negative-age 
dependence solely among younger firms, thus supporting the underlying premises of learning models of industry dynamics (Jovanovic, 1982, Ericson and Pakes, 1995) and capabilities, and positional advantage arguments based on the resource-based view of the firm. However, they found no evidence to support the liability of ageing. Our first hypothesis captures the uncertain and complex non-linear relationship between age and the hazard rate.

$\mathrm{H1}$ : The probability of firm exit decreases with age but rises again in the later stages of the firm lifecycle.

Many studies find that larger firms have lower hazard rates than their smaller equivalents (Esteve-Pérez and MañezCastillejo, 2008, Fackler et al., 2013, Fackler et al., 2014). Small firms entering at a sub-optimal scale face a larger cost disadvantage. The greater this disadvantage, the faster the firm will exit, unless it can innovate or find some other vehicle by which to grow. This is referred to as the 'liability of smallness'. Other liabilities of smallness include having lower organisational capital, undiversified product portfolios, and difficulties in accessing finance (Mueller and Stegmaier, 2015). The latter influences the small firm's ability to cope with macroeconomic shocks. Empirical work by Fackler et al. (2013) finds that the liability of smallness is less pronounced in more mature firms. Mueller and Stegmaier (2015), in examining bankruptcy risk, find negative size dependence for mature firms only. Current, rather than initial, firm size is adopted here, in the same way as with Fackler et al. (2013). This indicates the small firm's current level of efficiency and whether the small firm grew post-entry, see Mata et al. (1995).

$\mathrm{H} 2$ : Smaller firms face a higher hazard rate than larger firms, but the hazard rate of mature smaller firms is unaffected or increases with reductions in size.

Structural market conditions such as economies of scale, capital intensity, lacklustre growth and new entry heighten the hazard rates of young firms (e.g. Audretsch and Mahmood, 1995, Audretsch, 1995, Coad, 2018). Features that lower the hazard rate of young firms include larger initial size (Bernard and Jensen, 2007), higher price cost margins, innovativeness, entrepreneurial regimes, and fast growth markets (Mata et al., 1995, Jung et al., 2018). In mature firms, we expect that these factors are no longer barriers. Instead, their effects are either insignificant or promote the survival of the firm by lowering its hazard rate. An environmental shock is expected to alleviate competitive pressures exerted upon mature cohorts, through reduced new entry (Caballero and Hammour, 1994), while exacerbating the hazard rate of young firms, as they struggle to accumulate the resources to overcome barriers to survival. Bellone et al. (2008) examined how structural conditions affected the probability of exit over the lifecycle of French manufacturing firms. In general, they find that industry conditions largely affect the hazard rates of young firms, rather than mature firms. Similarly, Audretsch (1995) and Coad (2018) note that the effects of economies of scale are weakened, once the firm has survived the formative years of trading. We hypothesise:

H3: The hazard rate of younger firms is heightened by negative structural market conditions, whereas the hazard rate of mature firms is unaffected or positively affected by structural market conditions.

Incumbent firms in high-technology industries face a lower probability of survival than their equivalents in lowtechnology industries, due to the rapid obsolescence of initial endowments in innovative environments (Audretsch, 1995, Audretsch and Mahmood, 1995, Esteve-Pérez and Mañez-Castillejo, 2008). Such regimes favour innovative entry. Ejermo and Xiao (2014), examining data for Sweden, find that apart from knowledge-intensive and lowknowledge-intensive services, all technology sectors exhibit lower hazard rates than the low-technology firms. In contrast, for Germany, Strotmann (2007) finds no evidence that high/medium-technology manufacturing firms have a lower hazard rate than other sectors. Earlier work by Audretsch (1995) finds that a highly innovative environment constituted a barrier to survival in the years immediately post-entry, but that its effect diminished over time. Following Ejermo and Xiao (2014), Hypothesis 4 includes technology and knowledge intensive sectors.

$\mathrm{H} 4$ : The hazard rate of young firms in the high-technology manufacturing sectors and knowledge-intensive sectors is lower than that in other sectors (e.g. low-technology manufacturing, low-knowledge services).

Evidence is fairly conclusive on the sensitivity of hazard rates to the economic cycle. Firms face a higher hazard rate in recessions (Ejermo and Xiao, 2014, Esteve-Pérez et al., 2008, Geroski et al., 2010, Box, 2008, Fotopoulos and Louri, 2000). Unfavourable macroeconomic conditions at founding have been shown to raise the likelihood of 
exit. For Portuguese firms, Geroski et al. (2010) found that adverse founding conditions can have persistent effects for several years. Fotopoulos and Louri (2000) for Greek firms and Box (2008) for Swedish firms found that firms established closer to economic downturns have an increased exposure to failure. While Boeri and Bellmann (1995) found that exits in German manufacturing were unresponsive to the economic cycle, they also found that older plants were more likely to shrink in response to exogenous shocks. This leads us to:

H5: Firms founded in adverse economic conditions face a higher hazard rate.

H6: Hazard rates of mature firms are more sensitive to economic downturns, whereas hazard rates of newly founded firms are less sensitive to economic downturns.

The local regional economy also has a considerable impact on firm entry, survival and growth (see Frenken et al. (2015). Agglomeration effects contribute to firm exits through reduced local demand arising from declining regional population, incomes and business activity, and local supply factors such as the regional quality and specialisation of labour (Ciccone and Hall, 1996, Storey and Wynarczyk, 1996). Few studies on firm exits consider spatial aspects. Findings to date on studies of firm survival are contradictory. Strotmann (2007) finds that businesses located in rural regions have a greater chance of survival than those located in urban regions. In concordance, Renski (2011) finds that new manufacturing and professional services firms in the metropolitan urban areas have significantly lower survival rates, relative to urban and rural and non-metro areas in the US. Huiban (2009) reports similar findings for France. In contrast, Fotopoulos and Louri (2000) find that the location of Greek manufacturing firms in the capital (Athens), versus the rest of the country, affects survival positively, especially where smaller firms are concerned. A limited impact is found in other studies. Littunen (2000) finds that location does not influence the survival of the young small Finnish firms. Globerman et al. (2005) also find a very limited impact of location on firm survival for Canadian information technology firms. Tsvetkova et al. (2014) finds, for US computer and electronic product manufacturing firms, that local knowledge spillovers do not convert into lower hazard rates. Spatial influences on firm exits, considered here in Hypothesis 7, have not been examined at different points in the firm lifecycle, though agglomeration effects have been shown by Rigby and Brown (2015) to benefit young and old firms in different ways.

H7: Young firms located in urban areas face a higher hazard rate than firms located in rural regions.

\section{DATA, METHODS AND INITIAL RESULTS}

Irish business demography data covering all sectors (NACE Rev. 2 Sectors A-U), collated annually from administrative sources by the Irish Central Statistics Office (CSO) between 2006 and 2010, is adopted in this paper. Principle variables recorded in the data are the number of active enterprises, enterprise births and deaths, and their associated NACE sector and contribution to employment. Enterprises are active if they have paid VAT, registered employees, or filed a corporation/income (with over $€ 50,000$ turnover) tax return. Enterprise deaths do not include exits from the population due to mergers, acquisitions, divestments or restructuring, or enterprises, which reactivated within two years (Eurostat, 2007). Since most firms in our sample are geocoded, we use firm location to incorporate attributes of the region. We use the enterprise birth year to identify the enterprise's birth cohort. Our final sample consists of 218,880 active enterprises (84\% of Irish active enterprises) in 2010 and 104,031 enterprise deaths (82\% of Irish enterprise deaths) 2006-2009, where the geographical location of the enterprise is known to county level. ${ }^{2}$

We adopt a cohort approach similar to that of Box (2008) to examine how the determinants impact the probability of exit by birth cohort. We examine five cohorts of firms: (1) firms founded prior to 1980 (5,332 firms, $14 \%$ exited); (2) firms founded between 1980 and 1989 (39,578 firms, 11.7\% exited); (3) firms founded between 1990 and 1999 (74,410 firms, $29.6 \%$ exited); (4) firms founded between 2000 and 2005 (75,469 firms, 35\% exited); and (f) firms founded between 2006 and 2010 (140,477 firms, 41.2\% exited). Focusing on these cohorts enables a detailed examination of the impact of firm and wider environmental factors on the exit rates of young, established and mature cohorts over the crisis period. Figure 1 shows that more firms exited from young and adolescent cohorts. The percentage exiting declines with age across the cohorts but rises again for the oldest cohorts who were founded

2 Further details on the sample are available from the authors. 
before 1980 supporting hypothesis 1 and 2 .

Figure 2, a smoothed hazard rate, provides further support for these hypotheses. This figure demonstrates that firm failure risk was higher for younger firms. It continued to rise for firms that were almost 20 years in business before falling again for firms over 55 years, before rising for firms trading up to 70 years. The fall and rise in the failure risk are repeated for older or third-generation businesses. The higher failure risk for older firms in the crisis coincides with periods when businesses require successors, either within or outside the family. Next, we briefly examine some of our key variables. ${ }^{3}$

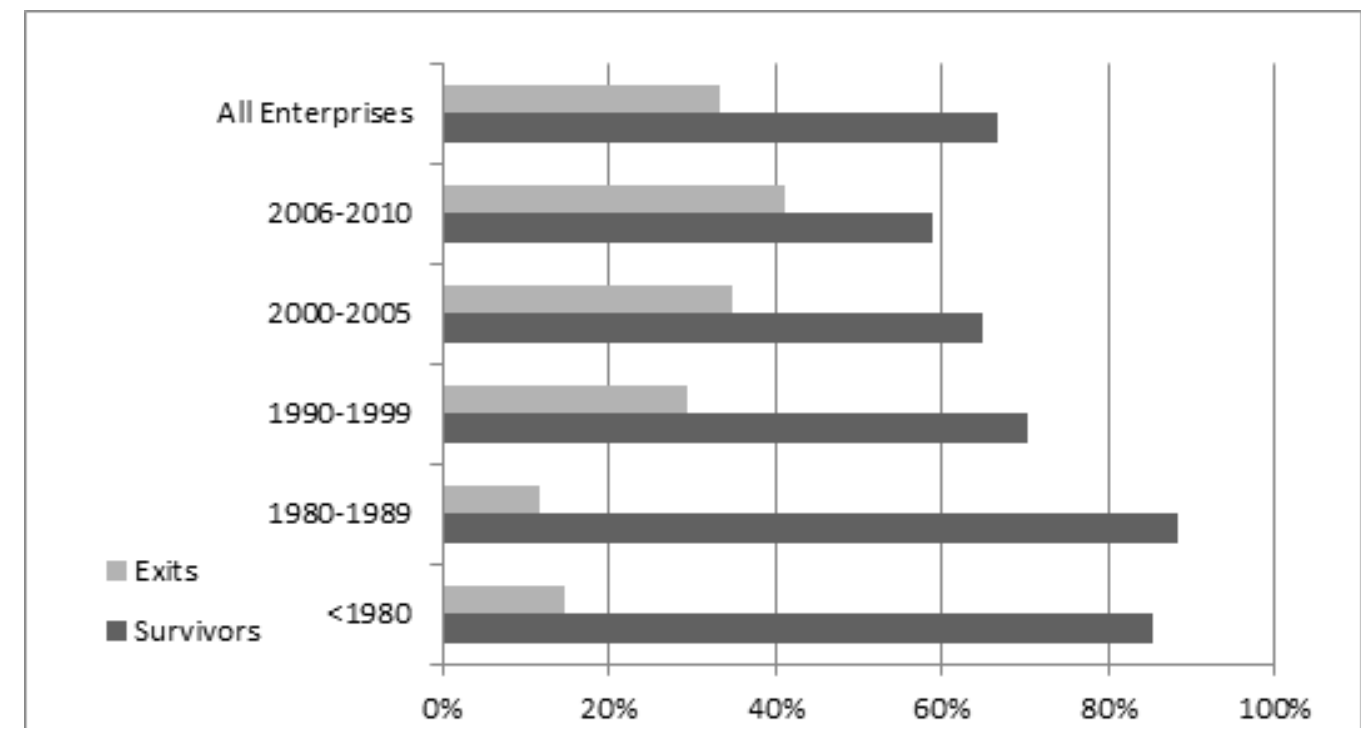

Figure 1. Percentage of Enterprise Deaths by Cohort during the Financial Crisis

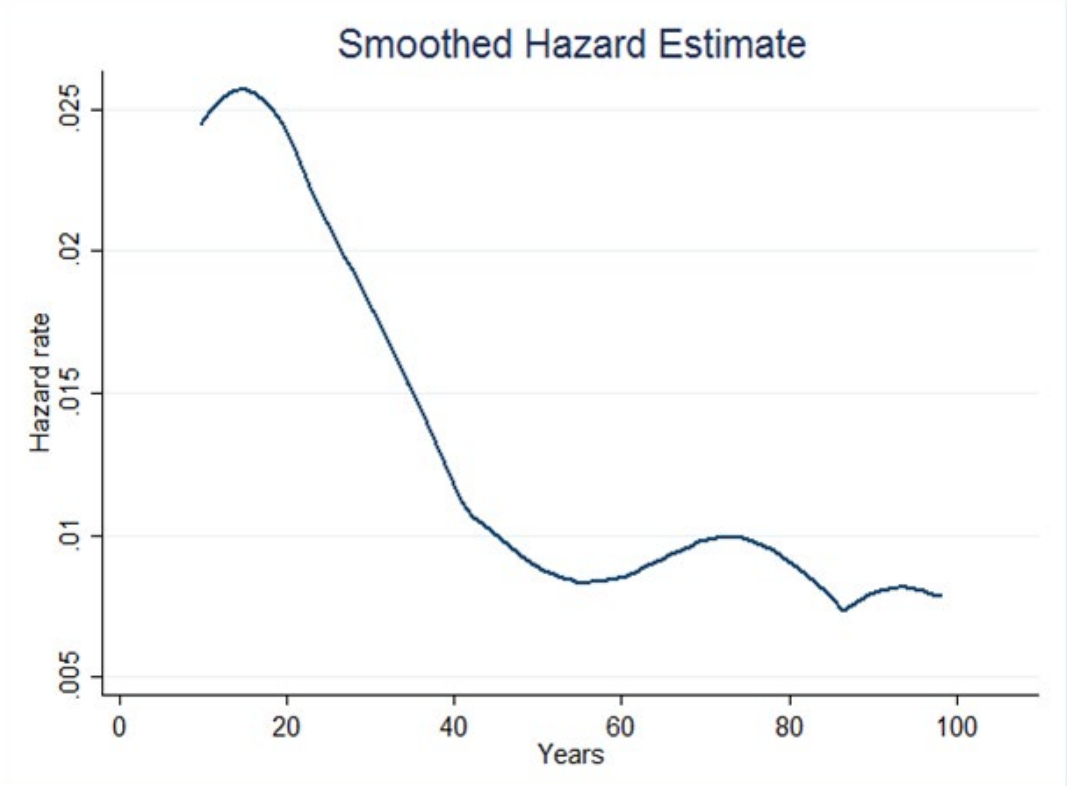

Figure 2. Non-parametric hazard function 


\section{Firm}

Size is approximated by the total number of people currently engaged in the business. Initial size is not available for firms founded in mature cohorts. Most firms in Ireland are micro firms ( $<10$ employees), with very few having more than 50 employees. We break the total number of people currently engaged in the business into five dummies $(0$, $1-4,5-9,10-49,50+$ employees) to capture the effect of micro, small- and medium-sized firms on the probability of exit. Figure 3 illustrates that the vast majority of exits from each cohort throughout the crisis had 1-4 employees.

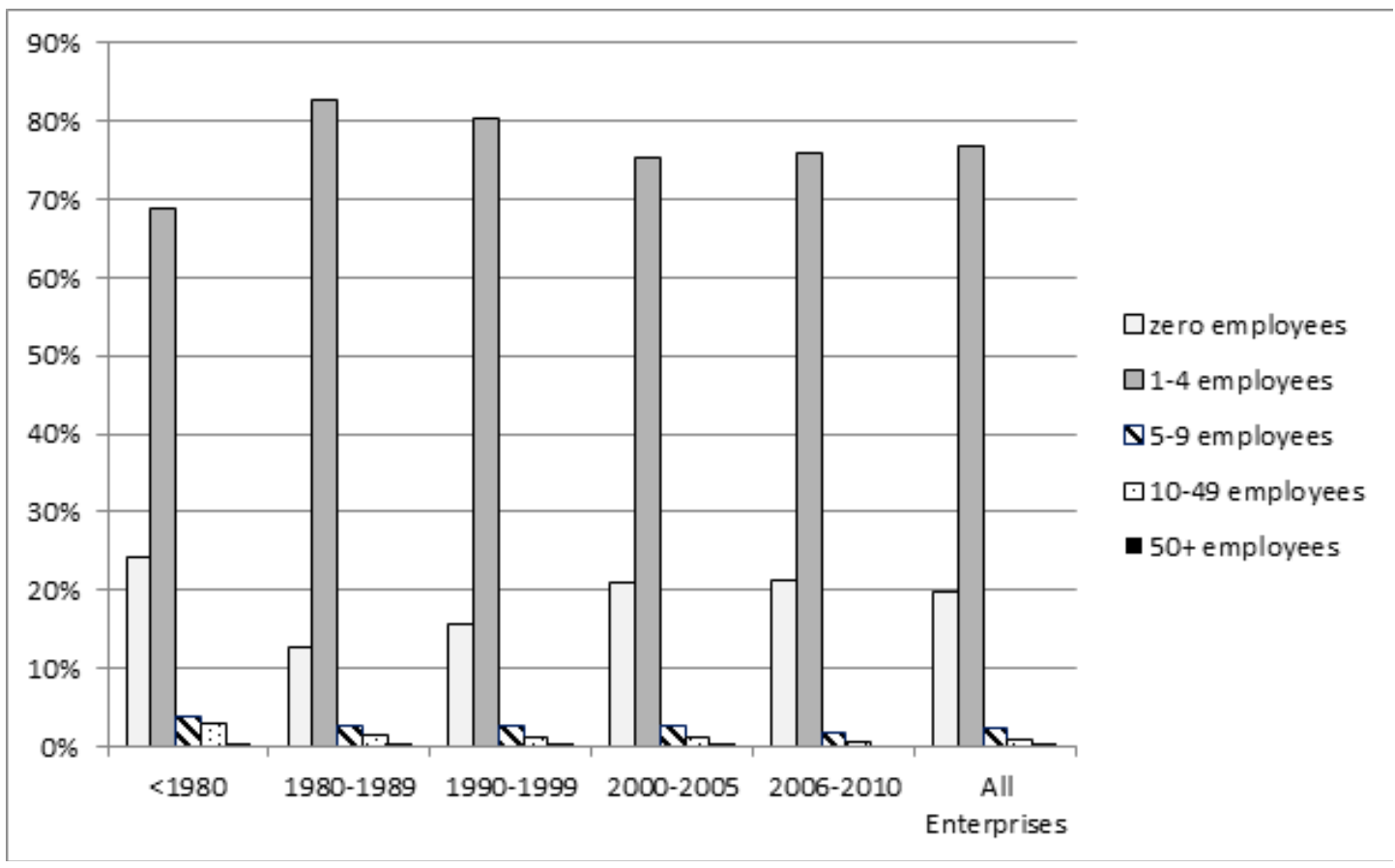

Figure 3. Size Distribution of Deaths in each Cohort during the Financial Crisis (\%)

\section{Industry}

Minimum efficient scale is measured, in accordance with Baldwin and Gellatly (2003), as a ratio of average new birth to firm size for each NACE Rev. 2 four-digit code to capture the influence of economies of scale. We also include the logarithmic of average capital intensity in each NACE Rev. 2 four-digit code. Average sectoral growth is measured by logarithmic difference in industry employment in each NACE Rev. 2 4-digit sector code between 2006 and 2010. The average entry rate is approximated in accordance with Lin and Huang (2008). If industries are cumulatively characterised by growth and high entry rates, the likely duration of firms is shorter. We include an interaction term to capture this effect. We also include a measure of the sunk costs associated with the industry, equating to 1 minus the minimum average entry and exit rate (Bernard and Jensen, 2007). The Herfindahl Index was measured at the NACE Rev. 2 four-digit level similar to that of Pe'er and Keil (2013), to capture the effect of concentration. The proxy for R\&D intensity, as with Strotmann (2007), was captured by three dummy variables; highand medium-high-technology (1/0) manufacturers, knowledge-intensive services $(1 / 0)$ and the reference category $(1 / 0)$, which includes low-technology manufacturing, low-knowledge services and other sectors, as defined by the Eurostat (2014) indicators of high-tech industry and knowledge-intensive services. Broad sectoral dummies for the significant sectors within Ireland were also included in the estimation. Figure 4 shows that the construction $(1 / 0)$ and other services sectors (1/0) suffered particularly among younger and adolescent cohorts, along with the professional and scientific sectors (1/0), whereas firms in agriculture/fishing/forestry (1/0), manufacturing (1/0) and wholesale/retail/repairs $(1 / 0)$ had the greater shares of exits in mature cohorts. 


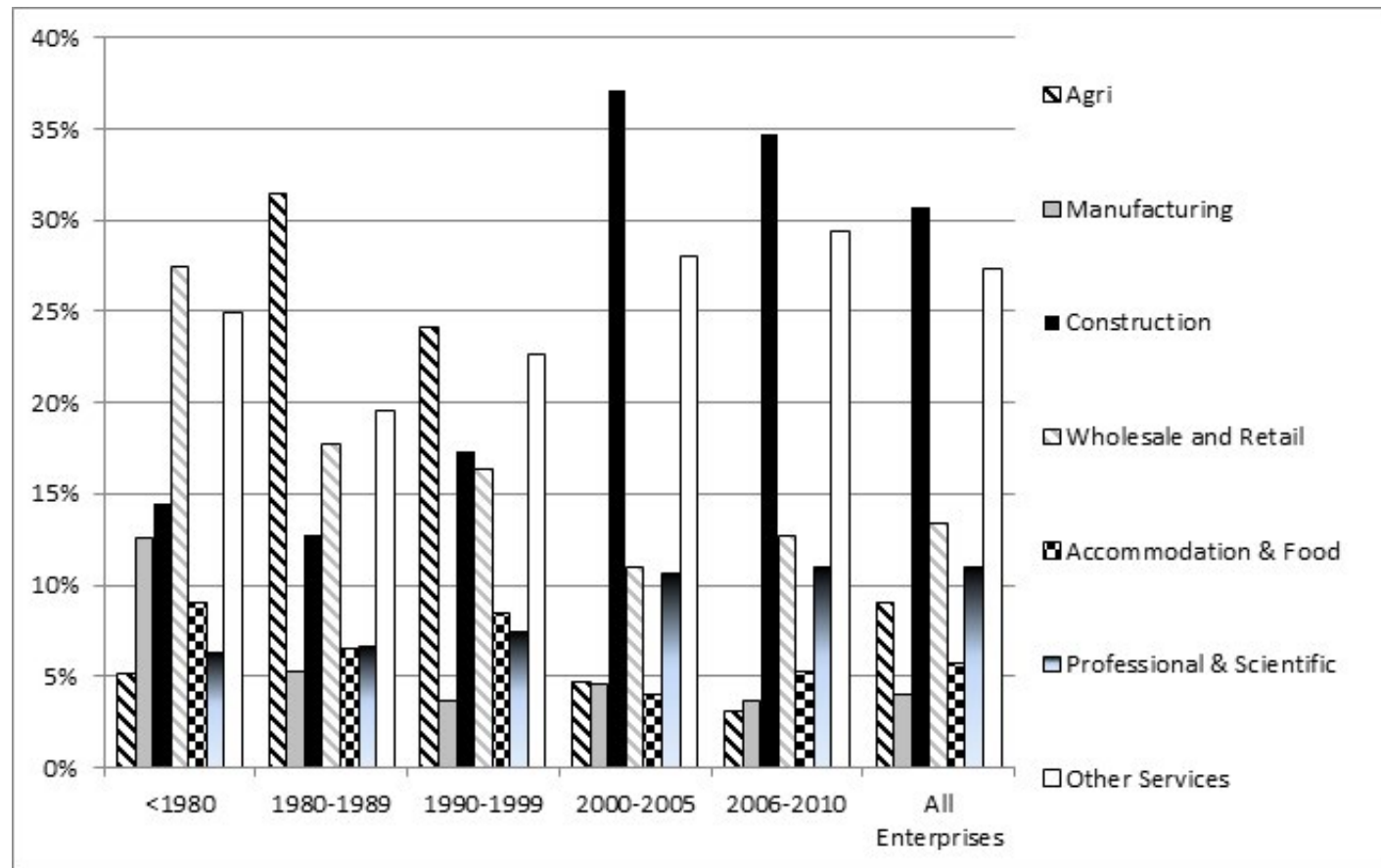

Figure 4. Sectorial Distribution of Deaths in each Cohort during the Financial Crisis (\%)

\section{Economic}

A measure of the growth in local unemployment over the period 2007 to 2010 is included, to capture local economic distress caused by the financial crisis in Ireland. Local unemployment is computed using county-level unemployment rates (2005 to 2012) for Ireland, compiled by Fitzpatrick and McQuinn (2014). We also include a dummy variable for firms that were founded before the financial crisis. This variable has a value of ' 1 ' for firms founded before 2007 and '0' otherwise. Such firms are expected to have a higher likelihood of survival (see Geroski et al. (2010).

\section{Regional}

An urban dummy was included, which took on a value of ' 1 ' if the electoral district (DED) population was more than 1,500 and zero otherwise. Most deaths were in urban districts, with little variation across cohorts (see Figure 5). We also control for attributes of the region in which the firm is located, using data on the local labour market in each DED obtained from the census 2006. We include the percentage of the local population at work, the percentage of the local population with third-level education, and the percentage of the local population employed across broad sectors. The location of the firm is controlled for using 25 county dummies. The sample size falls when the regional variables are controlled, as not all firms in the sample give their exact address. The model is therefore estimated twice - with and without these factors.

We examine influences on the hazard rates of mature and young cohorts of firms during the financial crisis, using a $\mathrm{CPH}$ models with an Efron correction for ties. We compare these estimates to accelerator failure time (AFT) models, to ensure the stability of the coefficients across estimation techniques. ${ }^{4}$ The $\mathrm{CPH}$ model is adopted, as it does not necessitate restrictive assumptions about the baseline hazard function. When the parametric form of the underlying baseline hazard function is unknown apriori, a flexible approach is preferable. It is also suitable, as our concern is not so much with the estimation of the underlying hazard function, but rather with the effect of the determinants on firm deaths, and whether these differ across cohorts.

The CPH model specifies the hazard function $h(t \mid x i t)$ as follows:

$$
h\left(t \mid x_{i t}\right)=h_{0}(t) \cdot \exp \left(x_{i}^{\prime} \beta\right)
$$


where $h(t \mid x i t)$ is the rate at which firms exit at time $t$ given that they have survived in $t-1$ and $h o(t)$ is the baseline hazard function (the parametric form of which is not identified) when all of the covariates are set to zero. The covariates capture the effect of explanatory variables on firm survival. The $\mathrm{CPH}$ model assumes that the hazard function is continuous and therefore that the firms can be precisely ordered in calendar time, regarding their time of failure. We estimate the $\mathrm{CPH}$ model using the Efron correction for ties, as we cannot detect the precise time (day or month) of closure, which implies that we have ties in our grouped form data.

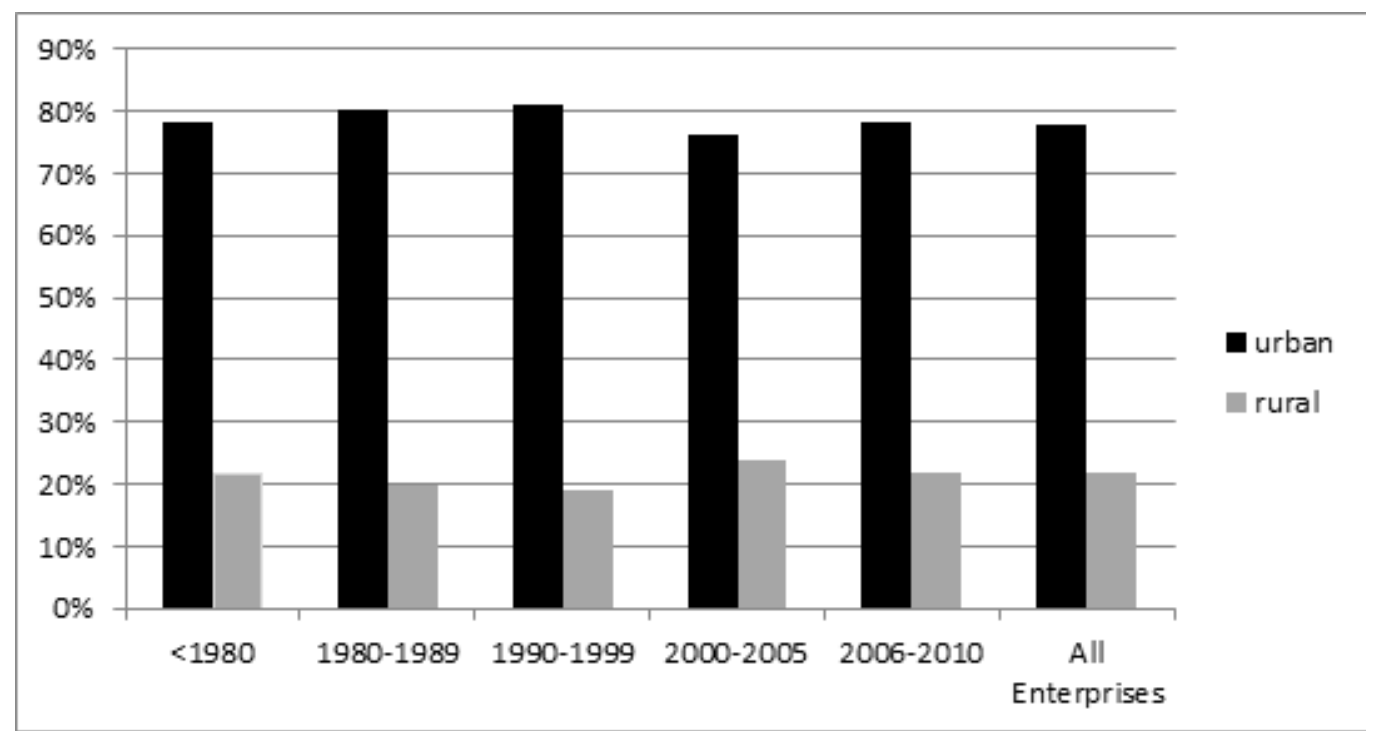

Figure 5. Regional Distribution of Deaths in each Cohort during the Financial Crisis (\%)

\section{RESULTS}

We present the $\mathrm{CPH}$ estimates in Table 1. A basic and extended model is estimated for each cohort and for the full sample, where the extended model includes characteristics of the region. Our dependent variable is the hazard rate. A positive (negative) coefficient means that the equivalent variable increases (reduces) the instantaneous probability of exit, thereby decreasing (increasing) the firms' chance of survival.

\section{Firm}

Size class at the time of the crisis had the largest relative impact on the probability of exit. A significant positive coefficient on the dummy variables for micro firms with zero employees, 1-4 employees and 5-9 employees in the full sample estimates (Columns XI-XII), and also in the estimates for each cohort (Columns I-X), indicated that micro firms face a lower likelihood of survival during the crisis period, in comparison with small firms with 10 to 49 employees, thus providing some support for Hypothesis 1. Firms with zero employees face the highest hazard rates, which can be obtained by calculating $\exp (\beta i)$ in Table 1, followed by firms with 1-4 employees, and so forth. Examining the percentage change in the hazard rate (Cleves et al., 2008), when the micro-firm size dummy, such as that for firms with 5-9 employees, turns from a value of ' 0 ' (from a small firm 10-49 employees) to '1' (a micro firm with 5-9 employees) which is calculated as [ $\exp (\beta i)-1]$, we find that the percentage increase in the hazard is much higher for firms founded before 1980 , equal to $83 \%$ as per [exp(0.6038)-1], in comparison with the analogous percentages for firms founded $1980-1989$ of $56 \%, 1990-1999$ of $74 \%, 2000-2005$ of $59 \%$, and 2006-2010 of $51 \%$. This pattern is similar for all micro-firm size dummies across the cohorts. Thus, the liability of smallness is pronounced, especially for mature cohorts, at least in times of crisis, which is contrary to Hypothesis 2 and earlier studies (Agarwal and Audretsch, 2001). However, it is supportive of, and extends recent work by, Fackler et al. (2013). A significant negative coefficient on the dummy variable for firms with $50+$ employees indicates that medium and large enterprises face a lower probability of exit during the crisis period, in comparison with small firms (10 to 49 employees). The coefficient on this size dummy variable is significant for firms founded after 1980. Larger 


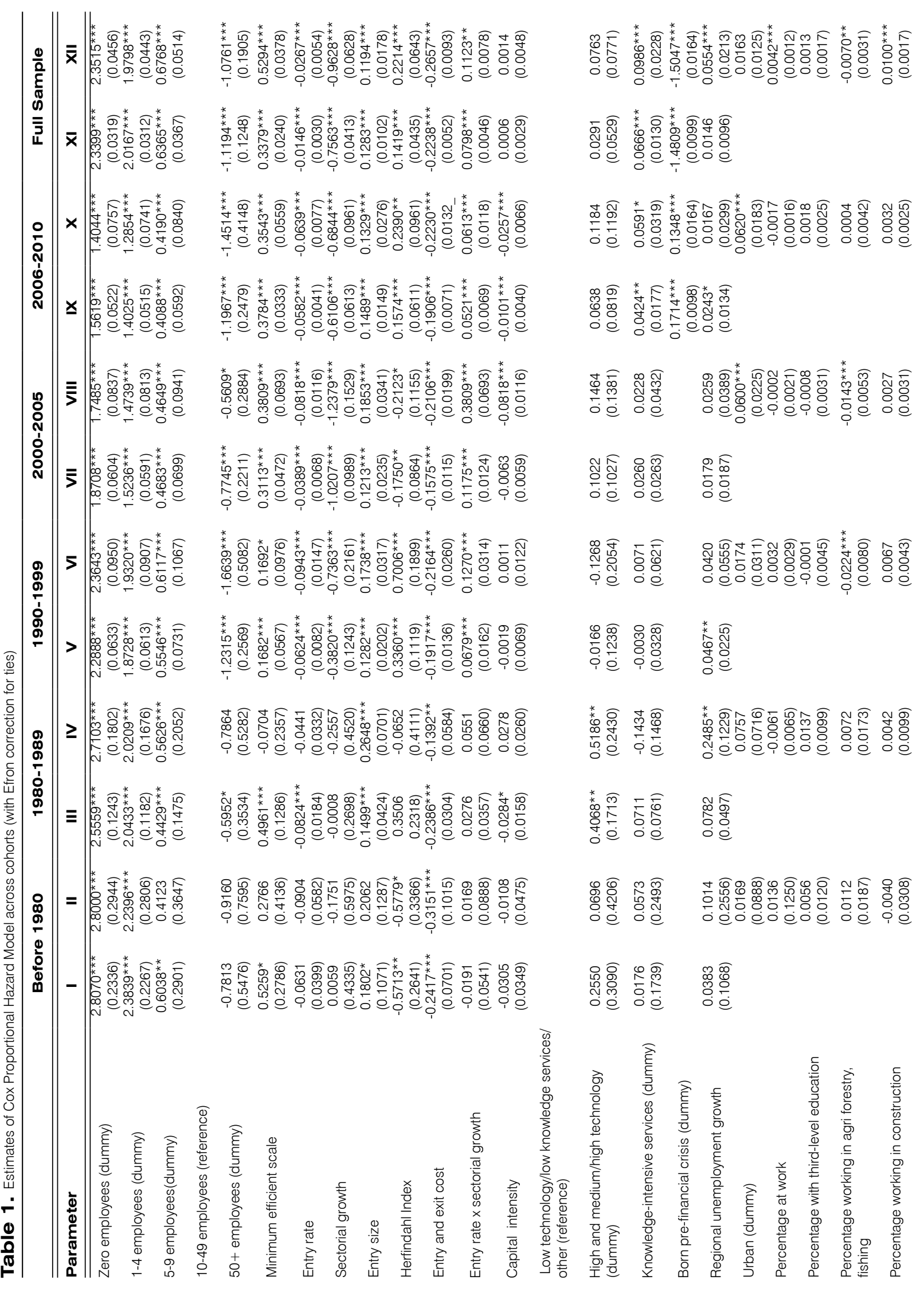




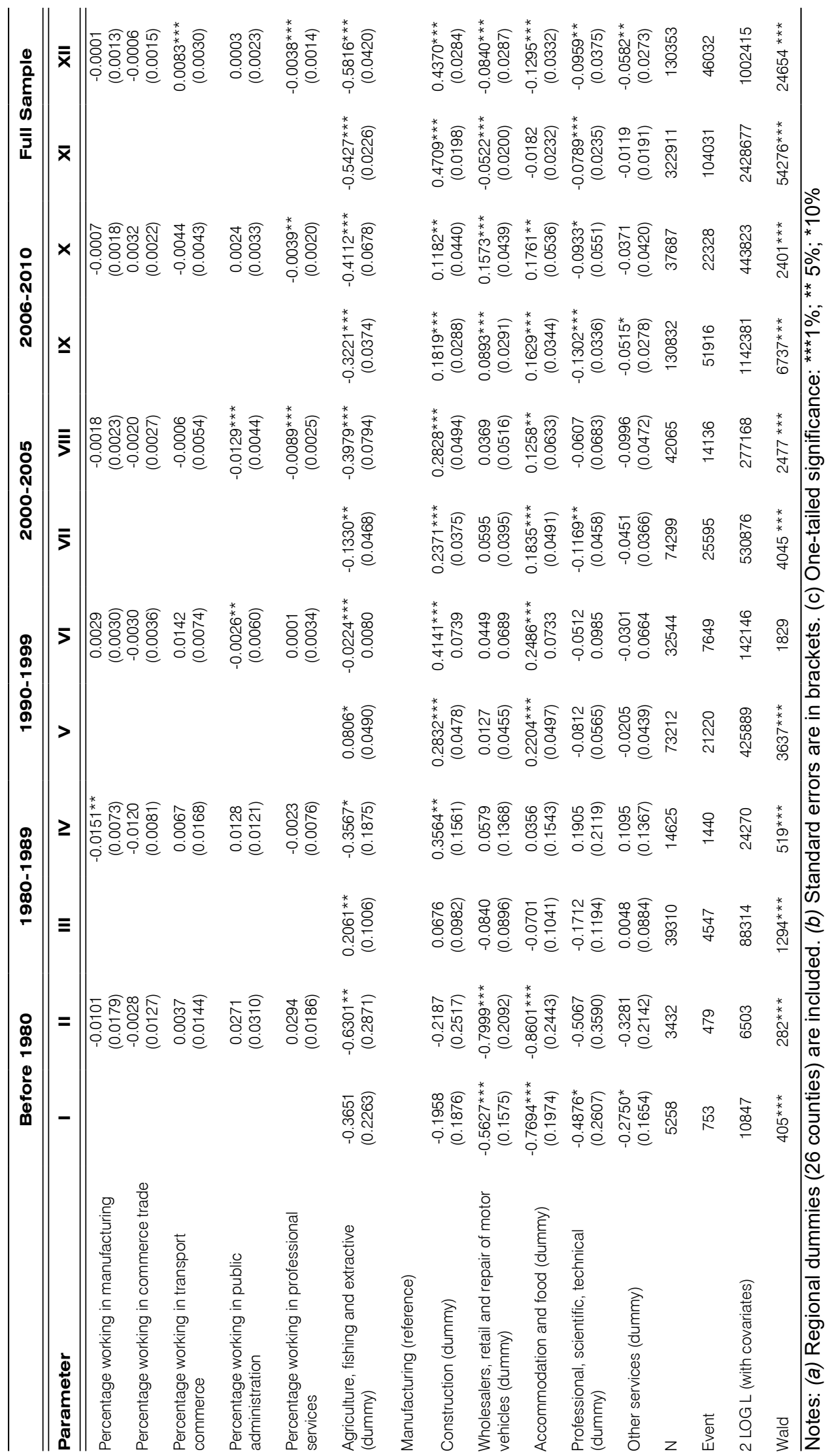


firms founded prior to 1980 do not face a significantly lower probability of exit during the crisis period, in comparison with small firms. The evidence suggests that current firm size is a key determinant of survival in times of crisis, particularly in mature firms.

\section{Industry}

Examining the full sample estimates (Columns XI-XII), firms operating in an industry with a higher minimum efficient scale and average size of new entrants over the period of the crisis are significantly more likely to exit, consistent with Strotmann (2007), whereas firms operating in industries with greater sunk costs over the crisis period face a significantly a lower likelihood of exit. Firms engaged in more concentrated markets over the crisis period captured by greater values of the Herfindahl index are also more likely to exit, while firms operating in growing sectors face a lower likelihood of exit. The latter effect is attenuated by higher entry rates into the sector over the crisis period, captured by the positive coefficient on the interaction variable between entry rate and sectorial growth, as found by Lopez-Garcia and Puente (2007). Contrary to expectations, firms operating in sectors with greater firm entry during the crisis period face a lower likelihood of exit, but similarly, this effect is diminished by higher sectorial growth, captured by the positive coefficient on the interaction variable between entry and sectorial growth.

Similar results are found for the individual cohorts. However, the hazard rates of firms founded prior to 1980 , and to a slightly lesser degree those founded between 1980 and 1989, are not as sensitive to changes in industry conditions over the crisis period. Cohorts founded during the crisis, or just prior to the crisis period, are much more sensitive to changes in these conditions, providing strong indicative support for the Geroski et al. (2010) findings, namely that founding conditions have a strong influence on the hazard rate and Hypothesis 3 . For firms founded from 1990 onwards, the sign and significance of the coefficient on minimum efficient scale (+), entry rates $(-)$, sectorial growth rates (-), entry rates $x$ sectorial growth (+), entrant size $(+)$ and entry and exit cost $(-)$ correspond with those of the full sample estimates (XII). It is largely only the sign and significance of the coefficient on the Herfindahl index and capital intensity which seem to vary across younger cohorts. When examining firms founded prior to 1980 , we find that the sign of the coefficients on the variables above largely correspond with those of the full sample estimates, but they are not significant.

Focusing on industry technological conditions, we find that knowledge intensive services firms are significantly more likely to exit, relative to firms operating low-technology and low-knowledge sectors over the crisis period (vis. full sample estimates) contrary to Hypothesis 4. This result holds for young firms founded from 2006 onwards, as opposed to older cohorts. This suggests knowledge intensive services firms are operating in a technological regime which favours innovative activity by incumbents, rather than innovative entry. We find no significant difference in the hazard faced by high- and medium-high-technology manufacturers and the reference dummy, except in the 1980 to 1989 cohort, where high- and medium-high-technology manufacturers face a higher probability of exit, as consistent with the findings of Agarwal and Sarkar (2002). Incumbent firms in high-technology industries face a higher probability of exit than their counterparts in low-technology and low-knowledge industries. The latter finding is indicative of a regime in favour of innovative entry, rather than innovative activity by incumbents.

When examining sectorial effects in the full sample estimates, we find that construction firms face a significantly higher probability of exit than manufacturing firms, while firms in agriculture, fishing and extractive industries, wholesalers, retail and repair of motor vehicles and professional, scientific and technical sectors face a significantly lower probability of exit than manufacturing firms. Firms operating in other services and in accommodation and food also face a significantly lower probability of exit, when agglomeration variables at DED level are controlled for. The pattern is similar for the cohort of firms founded amid the crisis (2006-2010), except for wholesalers, retailers and repair of motor vehicles firms and firms operating in the accommodation and food sector, which were significantly more likely to exit, in comparison with manufacturing firms also founded at that time. The significant and positive coefficient on construction and accommodation and food sector dummies was clearly evident in firms founded from 1990 onwards. Agriculture, fishing and extractive industries in general show a lower probability of exit in younger establishments founded from 2000 onwards. Mature firms (founded before 1980) operating in the agriculture, fishing and extractive (extended model only), wholesalers, retailers and repair of motor vehicles, accommodation and food, professional, scientific and technical and other services sectors were significantly less likely to exit, in comparison with manufacturing firms. The survival of mature manufacturing and construction firms was threatened more than services industries. 


\section{Economic}

Firms founded before the financial crisis are significantly less likely to exit during the crisis and face a much lower hazard rate when examining the full sample estimates, as is consistent with Esteve-Pérez and Mañez-Castillejo (2008). The magnitude of the impact on the hazard rate is sizeable at $77 \%$. This indicates that macroeconomic conditions at founding have a significant influence on a firm's chances of survival, supporting Hypothesis 5 . The result for the 2006 to 2010 cohort differs. A significant and positive coefficient was obtained, when those firms founded immediately prior to the crisis faced a higher probability of exit. It is thus not just the conditions in the year of founding, but in the immediate period following this event, that can influence the firm's survival chances. When examining the effect of regional unemployment growth per county on the hazard facing firms, we find that it raises the hazard rates of firms in the full sample (Column XII), when attributes of the local region are controlled for (impact on hazard rate of $6 \%$ ). The coefficient on regional unemployment growth is also positive and significant for young firms (2006-2010 cohort, Column IX) and more mature cohorts, when examining estimates of the reduced model for firms founded 1990 and 1999 (Column V), and the extended model for firms founded between 1980 and 1989 (Column IV). The magnitude of the impact on the hazard rates is considerably larger for firms founded in 1980 and 1989 at $28 \%$, in comparison with the younger cohorts at 5\% and $2 \%$ for firms founded in 1990-1999 and 2006 to 2010. Thus, older cohorts seem to be more sensitive to the economic cycle, which corresponds with the findings of Boeri and Bellmann (1995) and supporting hypothesis 6.

\section{Regional}

Examining the influence of agglomeration approximated by the urban dummy, we find that being located in an urban area raises the likelihood of exit for younger cohorts, as is consistent with Strotmann (2007) and thus supporting Hypothesis 7. The coefficient of the urban dummy is not significant for the full sample estimates but is positive and significant for firms founded after 2000. Thus, agglomeration seems to affect the survival chances of younger cohorts, as opposed to more mature cohorts. The magnitude of the percentage change in the hazard rate is low for firms founded between 2006 and 2010 (6.2\%) and for firms founded between 2000 and 2005 (6.4\%).

When examining attributes of the local region at DED level, we find that firms operating in districts that have a higher percentage of individuals in employment face a higher hazard rate over the crisis period (Column XII). This effect is not significant for any distinct cohort. Its impact on the hazard rate is low, at $0.4 \%$. Districts with a higher percentage of third-level graduates have no significant influence on the survival chances of firms located in these areas during the period of the crisis. Urban districts have a significantly higher mean percentage of people in employment ( $F$ Statistic $=666, p$-value $<0.0001)$ and with third-level education ( $F$ Statistic $=13627, p$-value $<0.0001)$.

In the full sample, firms located in districts with a high percentage of construction workers (1\%) and workers in transport (8\%) face a higher probability of exit over the crisis period, whereas firms located in districts with a high percentage of agriculture, forestry and fishing workers $(-0.7 \%)$ or/and professional services workers $(-4 \%)$ face a lower hazard rate over the crisis period (with associated impacts on the hazard rate of exiting in parentheses). Isolating cohort effects, we find that firms in younger cohorts (founded from 2000 onwards), located in districts with a high percentage of professional services workers, face a lower hazard rate over the crisis period. Firms in less-mature cohorts (founded from 1990 to 2005), located in districts with a high percentage of agriculture, forestry and fishing, and public administration workers, also face a lower hazard rate over the crisis period. Mature firms (1980-1989 cohort) operating in districts with a high percentage of manufacturing workers also face a significantly lower probability of exit. Urban districts have a significantly higher mean percentage of people in trade commerce ( $F$ Statistic $=666, p$-value $<0.0001$ ) and in transport commerce ( $F$ Statistic $=13627, p$-value $<0.0001)$, otherwise the mean percentage workers is higher in rural regions, with respect to the industries above. The reduction in the probability of exit is tentatively in support of evidence of a higher likelihood of survival in rural regions, except unsurprisingly, the construction industry. In general, agglomeration seems to affect younger cohorts more than mature cohorts, but the percentage change in the hazard rate is low in magnitude, in comparison with those of firm size and industry conditions.

\section{CONCLUSIONS}

In this paper, we examine the influence of an array of firm, industry, economic and regional determinants on the hazard rates of a large representative sample of young, established and mature firms during the crisis period 2006 to 2010 
in Ireland. From our empirical investigation, we find that the exit behaviour of young and mature firms is explained by different determinants. Specifically, we find that the liability of smallness is more pronounced for more mature micro firms than for younger counterparts founded amid the crisis. This is contrary to expectations, but supportive of the liability of ageing. By contrast, the hazard rates of mature firms are not as sensitive to changes in industry conditions over the crisis period. Younger cohorts are much more sensitive to changes in these conditions, as is consistent with Bellone et al. (2008). Structural conditions at founding have a strong influence on the hazard rate.

Exit behaviour from knowledge-intensive industries confirm the liability of newness. Firms founded during the crisis period in industries which are knowledge intensive faced a significantly higher probability of exit than those which entered medium-low and low- technology manufacturing and low-knowledge or other services industries. The estimates suggest a routinised regime in favour of the innovative activity of incumbents, rather than innovative entry in knowledge intensive services. The significantly higher probability of exit facing established high and medium-hightechnology manufacturing firms confirms the liability of ageing. The higher probability of exit of construction and accommodation and food firms related to manufacturing firms during the crisis can largely be explained by a narrowing of the market within these sectors. Firms that are more than 30 years old at the time of the study in the services industries are significantly less likely to exit, in comparison with manufacturing firms, thus indicating that manufacturing firms are much more subject to liability ageing due to obsolescence and/or senescence during the crisis.

From a regional perspective, it is also the younger firms that seem to suffer. Agglomeration and industry-related skills at a regional level affect younger cohorts more than mature cohorts. However, their impact on the hazard rate is low, in comparison with the impact of firm size and industry conditions. In response to economic conditions, firms founded after the crisis have a much higher probability of exit than those founded prior to the crisis, but not in comparison with those founded immediately prior to the crisis (at the end of the good times). Entrepreneurs who founded firms during the crisis perhaps did so knowingly. The hazard rates of young firms are influenced by regional unemployment, but to a lesser degree than those influencing mature cohorts. This, again, demonstrates the importance of considering the influence of regional determinants on mature, as well as young, firms.

The novel comparison of the estimate's pre-crisis, with those during the onset of the crisis, enables an analysis of true crisis effects and effects that are invariant with macroeconomic shocks. Larger firms, firms located in rural regions, and knowledge-intensive service business are less likely to exit pre-crisis and during the crisis. Smaller firms and younger firms are more likely to exit pre-crisis and during the crisis. Furthermore, firms that are jointly small and new are also more likely to exit under different economic environments. Older firms, in line with the findings of Boeri and Bellmann (1995), are more acutely affected during a crisis. They are culled earlier on in the crisis and hazard rates faced by firms with joint liabilities of smallness and ageing are more acute during a crisis.

Our results provide significant evidence that small and young firms face increased hazard rates, which means they might benefit from targeted policy support, in order to improve their probability of survival. While the OECD (2019) has highlighted that there are already significant supports for SMEs and entrepreneurial endeavours in Ireland, there is no unified SME and entrepreneurship policy document. There is an overarching enterprise policy document in place for Ireland, Enterprise 2025 Renewal, but this document is not specific to small, young firms, which have been identified as most at risk of exit. It also includes large and established enterprises. The main policy document targeting smaller firms, the National Policy Statement on Entrepreneurship (NPSE) focuses on entrepreneurship, rather than existing SMEs, and expired in 2019. This creates a vacuum in the policy landscape for these vulnerable younger smaller firms which, we suggest, in line with the OECD (2019), could be addressed through a unified policy document specifically targeted at existing small, young firms. Also, while the general business conditions are favourable towards smaller enterprises, two specific points emphasised by the OECD (2019), which are particularly detrimental to smaller and younger firms, are identified. Specifically, they highlight access to finance and rising skills shortages as particularly affecting SMEs. These problems are partly holdovers of the economic crisis of 2008, where the availability of bank credit - one of the critical facilitators of credit for smaller firms dried up. Also, emigration and cutbacks in educational programmes contributed to rising skill shortages. These are ongoing issues that could partially explain our findings of heightened risk for smaller and younger firms, which necessitate policy intervention.

Though we can identify firms that are more likely to exit during a crisis, it is challenging for policymakers to develop programmes to assist struggling businesses during severe downturns. It is hard to put together a comprehensive or even a targeted set of criteria, in terms of who should be supported and who should not. On aggregate, there is suggestive evidence that younger firms seem to suffer more than mature and established firms, but this is also true, though lower in intensity, in times of economic prosperity. Any policy - whether supportive of all or targeted 
groups (e.g. specific industries, new starts) - that is implemented is likely to have an associated deadweight and/or substitution effect (see Santarelli and Vivarelli (2007). Subsidies to new starts that would have survived despite such support represents deadweight, whereas subsidies for established firms that would have exited the market without the support represents a substitution effect. Relying on market selection, improvements in business and institutional conditions for all firms (e.g. reducing barriers to entry, cutting red tape and bureaucracy, and ensuring an efficient banking system and an attractive tax system), and reducing capital market imperfections, is arguably superior to directly subsidising mature, established or young businesses to prevent firm exits. In general, building an industrial base that is resistant to economic shocks is also a preferable approach to industrial policy (e.g. encouraging firms to increase scale, supporting knowledge-based services firms, encouraging rural entrepreneurship).

While we have presented, in this paper, the influence of determinants on the hazard rates of a large representative sample of firms during the crisis period, we cannot distinguish between voluntary closures and involuntary closures, as in the recent work by Mueller and Stegmaier (2015) and Balcaen et al. (2012). We are also limited in examining other causes of business deaths, such as inadequate management skills and insufficient capital (Ropega, 2011), due to limited data on the entire stock of business in Ireland. Richer data is available for smaller samples of firms, but smaller sample size limits an analysis such as the above on a representative sample of particularly mature survivors and exits. It would be a consideration for further research if or when such data becomes available. However, the study does provide unique evidence on how young, established and mature firms interact with their environment in different ways in times of crisis.

\section{References}

Agarwal, R. and Audretsch, D.B. (2001). 'Does entry size matter? The impact of the life cycle and technology on firm survival'. The Journal of Industrial Economics, 49, 21-43.

Agarwal, R. and Sarkar, M. (2002). 'The conditioning effect of time on firm survival: An industry life cycle approach'. Academy of Management Journal, 45, 971-994.

Audretsch, D.B. (1995). 'Innovation, growth and survival'. International Journal of Industrial Organization, 13, 441-457.

Audretsch, D.B. and Mahmood, T. (1995). 'New firm survival: New results using a hazard function'. The Review of Economics and Statistics, 77(1), 97-103.

Balcaen, S., Manigart, S., Buyze, J. and Ooghe, H. (2012). 'Firm exit after distress: Differentiating between bankruptcy, voluntary liquidation and M\&A'. Small Business Economics, 39, 949-975.

Baldwin, J.R. and Gellatly, G. (2003). Innovation Strategies and Performance in Small Firms, Edward Elgar Publishing, Cheltenham, UK.

Barron, D.N., West, E. and Hannan, M.T. (1994). 'A time to grow and a time to die: Growth and mortality of credit unions in New York City, 1914-1990'. American Journal of Sociology, 100, 381-421.

Bellone, F., Musso, P., Nesta, L. and Quéré, M. (2008). 'Market selection along the firm life cycle'. Industrial and Corporate Change, 17, 753-777.

Bergin, A., Gerald, J.F., Kearney, I. and O'Sullivan, C. (2011). 'The Irish fiscal crisis'. National Institute Economic Review, 217, R47-R59.
Bernard, A.B. and Jensen, J.B. (2007). 'Firm structure, multinationals, and manufacturing plant deaths'. The Review of Economics and Statistics, 89, 193204.

Boeri, T. and Bellmann, L. (1995). 'Post-entry behaviour and the cycle: Evidence from Germany'. International Journal of Industrial Organization, 13, 483-500.

Box, M. (2008). 'The death of firms: Exploring the effects of environment and birth cohort on firm survival in Sweden'. Small Business Economics, 31, 379-393.

Caballero, R.J. and Hammour, M.L. (1994). 'The cleansing effect of recessions'. The American Economic Review, 84, 1350-1368.

Carbo-Valverde, S., Rodriguez-Fernandez, F. and Udell, G. F. (2016). 'Trade credit, the financial crisis, and SME access to finance'. Journal of Money, Credit and Banking, 48, 113-143.

Carreira, C. and Teixeira, P. (2011a). 'Entry and exit as a source of aggregate productivity growth in two alternative technological regimes'. Structural Change and Economic Dynamics, 22, 135-150.

Carreira, C. and Teixeira, P. (2011b). 'The shadow of death: Analysing the pre-exit productivity of Portuguese manufacturing firms'. Small Business Economics, 36, 337-351.

Cefis, E. and Marsili, O. (2005). 'A matter of life and death: Innovation and firm survival'. Industrial and Corporate Change, 14, 1167-1192.

Ciccone, A. \& Hall, R. E. (1996). 'Productivity and the density of economic activity'. American Economic 
Review, 86, 54-70.

Cleves, M., Gould, W., Gould, W.W., Gutierrez, R. and Marchenko, Y. (2008). An Introduction to Survival Analysis Using Stata, Stata Press, College Station, Texas.

Coad, A. (2018). 'Firm age: A survey'. Journal of Evolutionary Economics, 28, 13-43.

Ejermo, O. and Xiao, J. (2014). 'Entrepreneurship and survival over the business cycle: How do new technology-based firms differ?'. Small Business Economics, 43, 411-426.

Ericson, R. \& Pakes, A. (1995). 'Markov-perfect industry dynamics: A framework for empirical work'. The Review of Economic Studies, 62, 53-82.

Esteve-Pérez, S. and Mañez-Castillejo, J.A. (2008). 'The resource-based theory of the firm and firm survival'. Small Business Economics, 30, 231-249.

Esteve-Pérez, S., Mánez-Castillejo, J. A. and SanchisLlopis, J.A. (2008). 'Does a "survival-by-exporting" effect for SMEs exist?' Empirica, 35, 81-104.

Eurostat. (2007). Eurostat - OECD Manual on Business Demography Statistics [Online]. Luxembourg: Office for Official Publications of the European Communities: Eurostat. http://ec.europa.eu/ eurostat/ramon/statmanuals/files/KS-RA-07-010EN.pdf [Accessed 21 September 2017].

Eurostat. (2014). 'Eurostat indicators of High-tech industry and knowledge - intensive services, January 2014 Annex 3 - High-tech aggregation by NACE Rev. 2' [Online]. Eurostat. http://ec.europa. eu/eurostat/cache/metadata/Annexes/htec_esms an3.pdf [Accessed 21 September 2017].

Fackler, D., Schnabel, C. and Wagner, J. (2013). 'Establishment exits in Germany: The role of size and age'. Small Business Economics, 41, 683-700.

Fackler, D., Schnabel, C. and Wagner, J. (2014). 'Lingering illness or sudden death? Preexit employment developments in German establishments'. Industrial and Corporate Change, 23, 1121-1140.

Fitzpatrick, T. and Mcquinn, K. (2014). 'Unemployment and the crisis in the Irish mortgage market: A regional perspective. Coping with recession: A regional perspective conference. 2' [Online]. University College Cork. https://www.ucc.ie/ en/media/academic/centreforpolicystudies/3. KieranMcQuinn-UnemploymentandthelrishMortga geCrisis-ARegionalPerspective.pdf [Accessed 31 January 2020].

Fort, T.C., Haltiwanger, J., Jarmin, R.S. and Miranda, J. (2013). 'How firms respond to business cycles: The role of firm age and firm size'. IMF Economic Review, 61, 520-559.
Fotopoulos, G. and Louri, H. (2000). 'Location and survival of new entry'. Small Business Economics, 14, 311-321.

Frenken, K., Cefis, E. and Stam, E. (2015). 'Industrial dynamics and clusters: A survey'. Regional Studies, 49, 10-27.

Geroski, P.A., Mata, J. and Portugal, P. (2010). 'Founding conditions and the survival of new firms'. Strategic Management Journal, 31, 510-529.

Globerman, S., Shapiro, D. and Vining, A. (2005). 'Clusters and intercluster spillovers: Their influence on the growth and survival of Canadian information technology firms'. Industrial and Corporate Change, 14, 27-60.

Huiban, J.-P. 2009. (2009). 'Urban versus rural firms: does location affect labor demand?'. Growth and Change, 40, 649-672.

Jovanovic, B. (1982). 'Selection and the evolution of industry'. Econometrica: Journal of the Econometric Society, 50(3), 649-670.

Jung, H., Hwang, J. and Kim, B.-K. (2018). 'Does R\&D investment increase SME survival during a recession?'. Technological Forecasting and Social Change, 137, 190-198.

Lin, P.-C. and Huang, D.-S. (2008). 'Technological regimes and firm survival: Evidence across sectors and over time'. Small Business Economics, 30, 175-186.

Littunen, H. (2000). 'Networks and local environmental characteristics in the survival of new firms'. Small Business Economics, 15, 59-71.

Lopez-Garcia, P. and Puente, S. (2007). 'A comparison of the determinants of survival of Spanish firms across economic sectors'. In J. M. Arauzo-Carod and M. C. Manjon-Antolin (Eds.), Entrepreneurship, Industrial Location and Economic Growth, 161183. Cheltenham: Edwar Elgar.

Mata, J., Portugal, P. and Guimaraes, P. (1995). 'The survival of new plants: Start-up conditions and post-entry evolution'. International Journal of Industrial Organization, 13, 459-481.

Mueller, S. and Stegmaier, J. (2015). 'Economic failure and the role of plant age and size'. Small Business Economics, 44, 621-638.

OECD. (2019). SME and Entrepreneurship Policy in Ireland. OECD Studies on SMEs and Entrepreneurship. Paris: OECD Publishing.

Pe'er, A. and Keil, T. (2013). 'Are all startups affected similarly by clusters? Agglomeration, competition, firm heterogeneity, and survival'. Journal of Business Venturing, 28, 354-372.

Renski, H. (2011). 'External economies of localization, urbanization and industrial diversity and new firm 
survival'. Papers in Regional Science, 90, 473-502.

Rigby, D.L. and Brown, W.M. (2015). 'Who benefits from agglomeration?'. Regional Studies, 49, 28-43.

Ropega, J. (2011). 'The reasons and symptoms of failure in SME'. International Advances in Economic Research, 17, 476-483.

Santarelli, E. and Vivarelli, M. (2007). 'Entrepreneurship and the process of firms' entry, survival and growth'. Industrial and Corporate Change, 16, 455-488.

Stinchcombe, A.L. (1965.) Social structure and organizations', in: J March (ed.), Handbook of organizations, Chicago: Rand-McNally.

Storey, D.J. and Wynarczyk, P. (1996). 'The survival and non survival of micro firms in the UK'. Review of Industrial Organization, 11, 211-229.

Strotmann, H. (2007). 'Entrepreneurial survival'. Small Business Economics, 28, 87-104.
Tsvetkova, A., Thill, J.-C. and Strumsky, D. (2014). External Effects of Metropolitan Innovation on Firm Survival: Non-Parametric Evidence from Computer and Electronic Product Manufacturing and Healthcare Services. Applied Regional Growth and Innovation Models. In Advances in Spatial Science, 78, 83-106. Springer International Publishing. Springer, Berlin, Heidelberg.

Zarutskie, R. and Yang, T. (2016). 'How did young firms fare during the great recession? evidence from the Kauffman firm survey'. NBER Chapters, 253-290.

Zúñiga-Vicente, J. Á. and Vicente-Lorente, J.D. (2006). Strategic moves and organizational survival in turbulent environments: The case of Spanish banks (1983-97)'. Journal of Management Studies, 43, 485-519. 